\title{
Self-Regulation: Develop Study Skills in Online Higher Education
}

\author{
Goulão, M.F. \\ Universidade Aberta
}

\begin{abstract}
Teaching strategies, in online contexts, arise as a response to students' needs to achieve their learning goal. This kind of teaching requires different cognitive and affective skills. It is necessary to encourage student motivation to avoid dropping out. An important element in the online context is self-regulation of learning. According to Pachler and Daly (2011) "... self-regulation assumes active participation of learners at those levels in their own learning" (p. For Zimmerman (1998, 2000), corroborated by other authors, self-regulation is a process in cycle - Action planning (definition of objectives and strategies), process monitoring and strategies (achievement), and, finally, feedback and self-assessment. Our objective was to verify the justifications given by the students, on the one hand, to the assessments (self-evaluation phase) obtained. On the other hand, how they hoped to plan the next evaluation (definitions of objectives and strategies). Our study included 35 students online for the first time in this education system, and $70.6 \%$ female and $29.4 \%$ male. They selected the continuous assessment regime. Our objective was to verify the justifications given by these students, on the one hand, to the assessments (evaluation phase) obtained. On the other hand, how they hoped to plan the next evaluation (definitions of objectives and strategies). From the descriptive point of view, $44 \%$ of the students consider that the classification obtained does not correspond to their expectations. With $56 \%$ agreed with the classification obtained. Qualitative data are analyzed in the evaluation phase, considering 2 major categories, the Causality and Methodology that will be presented later. Such as the results of the planning. (working in progress).
\end{abstract}

Keywords: Online Learning, Adult Students, Motivation, Self-Regulation. 
